\title{
Rhodium Complexes in P-C Bond Formation: Key Role of a Hydrido Ligand
}

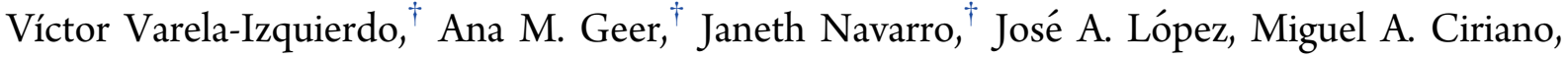 \\ and Cristina Tejel*
}

Cite This: https://dx.doi.org/10.1021/jacs.0c11010

Read Online

ACCESS | Lill Metrics \& More | 回 Article Recommendations | S1 Supporting Information

ABSTRACT: Olefin hydrophosphanation is an attractive route for the atom-economical synthesis of functionalized phosphanes. This reaction involves the formation of $\mathrm{P}-\mathrm{C}$ and $\mathrm{H}-\mathrm{C}$ bonds. Thus, complexes that contain both hydrido and phosphanido functionalities are of great interest for the development of effective and fast catalysts. Herein, we showcase the excellent activity of one of them, $\left[\mathrm{Rh}(\mathrm{Tp}) \mathrm{H}\left(\mathrm{PMe}_{3}\right)\left(\mathrm{PPh}_{2}\right)\right](\mathbf{1})$, in the hydrophosphanation of a wide range of olefins. In addition to the required nucleophilicity of the phosphanido moiety to accomplish the $\mathrm{P}-\mathrm{C}$ bond formation, the key role of the hydride ligand in $\mathbf{1}$ has been disclosed by both

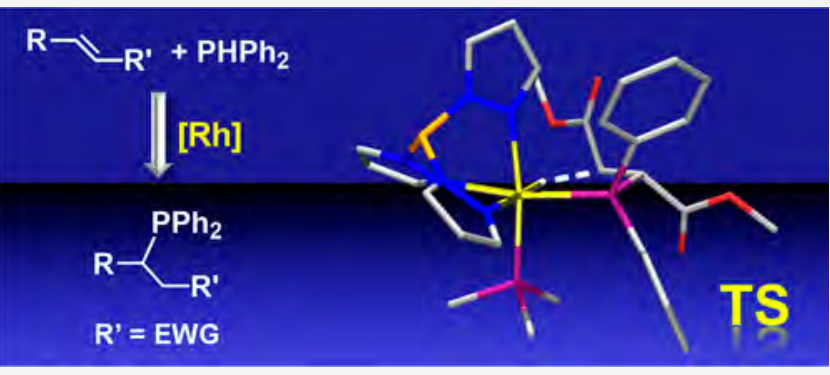
experimental results and DFT calculations. An additional $\mathrm{Rh}-\mathrm{H} \cdots$

$\mathrm{C}$ stabilization in some intermediates or transition states favors the hydrogen transfer reaction from rhodium to carbon to form the $\mathrm{H}-\mathrm{C}$ bond. Further support for our proposal arises from the poor activity exhibited by the related chloride complex $\left[\mathrm{Rh}(\mathrm{Tp}) \mathrm{Cl}\left(\mathrm{PMe}_{3}\right)\left(\mathrm{PPh}_{2}\right)\right]$ as well as from stoichiometric and kinetic studies.

\section{INTRODUCTION}

Carbon-phosphorus $(\mathrm{C}-\mathrm{P})$ bond formation is a key step in the synthesis of organophosphanes, which play essential roles as ligands for transition metal complexes and in organocatalysis as building blocks for medicinal and supramolecular chemistry and have extensive commercial applications. ${ }^{1}$ However, classical methodologies for the synthesis of organophosphanes suffer from safety concerns (handling corrosive and flammable compounds), use of protective groups that bring in additional synthetic steps, lack of selectivity, and limited scope. ${ }^{1 \mathrm{~d}, 2}$ Therefore, there has been a growing interest in the development of more efficient synthetic strategies, among which the net addition of a $\mathrm{P}-\mathrm{H}$ bond to unsaturated substrates is one of the most attractive due to the safety, selectivity, and $100 \%$ atom-economy provided by this approach. ${ }^{3}$ In particular, hydrophosphanation of alkenes/ alkynes is a powerful synthetic tool to create a plethora of compounds containing a $\mathrm{C}-\mathrm{P}$ bond such as secondary or tertiary phosphanes with new alkyl substituents. ${ }^{4}$

Among the wide range of catalysts with a $\mathrm{M}-\mathrm{PR}_{2}$ moiety reported for this reaction, ${ }^{5}$ our attention has focused on those arising from the oxidative-addition of the $\mathrm{P}-\mathrm{H}$ bond. This activation reaction eventually gives hydrido-phosphanido intermediates, allowing thus the entry of the phosphanido functionality into the coordination sphere of the metal in a simple and clean way.

From a mechanistic point of view, these intermediates can follow two main alternatives for the next $\mathrm{P}-\mathrm{C}$ bond formation step: either coordination of the alkene/alkyne followed by insertion into the $\mathrm{M}-\mathrm{P}^{6}$ or the $\mathrm{M}-\mathrm{H}^{7}$ bonds (inner-sphere pathway) or outer-sphere phospha-Michael additions. ${ }^{8} \mathrm{~A}$ further reductive-elimination reaction in the former case and a hydrido transfer to the intermediate carbanion in the latter one render phosphane complexes, in which a simple phosphane exchange closes the catalytic cycles (Scheme 1).

Rhodium complexes have been scarcely studied in this field. Particularly pertinent to the present work are the rhodium(III) hydrido-phosphanido intermediates observed by Tilley, which are suitable for phosphorus-sulfur coupling, ${ }^{9}$ and a rhodium(V) bis(hydrido-phosphanido) complex proposed by Brookhart in the catalytic dehydrocoupling of secondary phosphanes. ${ }^{10}$ More recently, N-heterocyclic carbene (NHC) rhodium(I) complexes have been shown to be efficient catalysts for the double hydrophosphanation of alkynes, ${ }^{11}$ whereas we have shown the influence of the ancillary ligands on the formation of mononuclear hydrido-phosphanido rhodium complexes ${ }^{12}$ and confirmed that some of them are intermediates in dehydrocoupling reactions. ${ }^{13}$

Received: October 19, 2020 
Scheme 1. Proposed Catalytic Cycles for Olefin Hydrophosphanation Involving Hydrido-phosphanido Complexes $^{a}$

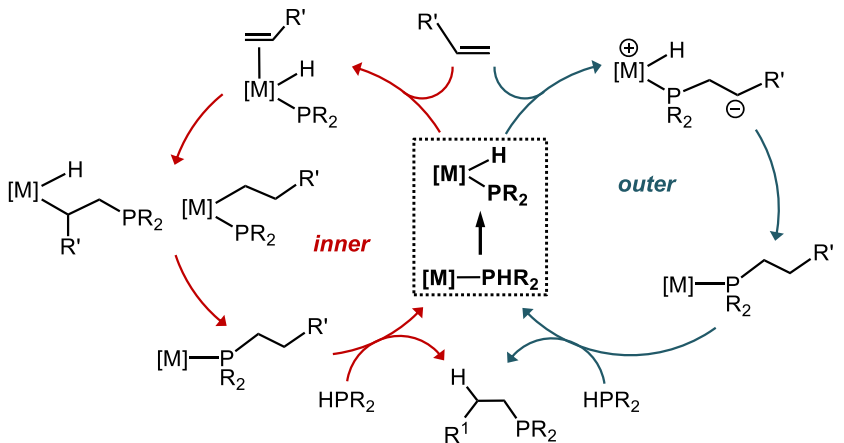

${ }^{a} \mathrm{R}^{\prime}$ = electron withdrawing group (EWG) for the cycle in blue.

Herein, we showcase a full study on the catalytic activity of a hydrido-phosphanido rhodium complex in the hydrophosphanation of alkenes with diphenylphosphane. We disclose the key role of the hydride ligand in providing a low energy pathway for the $\mathrm{C}-\mathrm{H}$ bond formation after the critical $\mathrm{P}-\mathrm{C}$ bond formation, supported by kinetics and in agreement with DFT studies. This key step seems to be the origin of its exceptionally good activity in olefin hydrophosphanation.

\section{RESULTS AND DISCUSSION}

Catalytic Assays. The hydrido-phosphanido complex $\left[\mathrm{Rh}(\mathrm{Tp}) \mathrm{H}\left(\mathrm{PMe}_{3}\right)\left(\mathrm{PPh}_{2}\right)\right](\mathbf{1})^{12}$ was examined as a catalyst for the hydrophosphanation with $\mathrm{PHPh}_{2}$ of the olefins listed in Table 1. All the reactions were fully selective to the antiMarkovnikov product, as typically observed for hydrophosphanation reactions, with no traces of the Markovnikov isomer detected by NMR spectroscopy.

Complex 1 was found to be extremely active in the hydrophosphanation of methylacrylate (MeAC), with a full conversion in less than $5 \mathrm{~min}$ at room temperature $(\mathrm{rt})$ even with very low catalyst loadings $(0.1 \% \mathrm{~mol}$ cat., entry 2$)$. Compared with other catalysts reported in the literature, ${ }^{4 \mathrm{e}, \mathrm{g}, 1, \mathrm{v}}$ complex 1 is, to the best of our knowledge, the fastest catalyst for the hydrophosphanation of methylacrylate with $\mathrm{PHPh}_{2}$.

Table 1. Synthesis of Functionalized Phosphanes Catalyzed by Complex $1^{a}$

\begin{tabular}{|c|c|c|c|c|c|c|}
\hline Entry & Alkene & Product $^{\mathrm{c}}$ & $1(\mathrm{~mol} \%)$ & Time $(\min )$ & Conv. $(\%)^{b}$ & Isolated yield (\%) \\
\hline 1 & Methylacrylate & & 5 & $<5$ & $>99$ & 98 \\
\hline 2 & Methylacrylate & & 0.1 & $<5$ & $>99$ & \\
\hline 3 & Methylacrylate & & 0.02 & 669 & 98 & \\
\hline 4 & Acrylonitrile & & 5 & 18 & $>99$ & 97 \\
\hline 5 & Acrylonitrile & & 1 & 116 & 95 & \\
\hline 6 & Dimethylfumarate & & 5 & 35 & $>99$ & 98 \\
\hline 7 & Dimethylfumarate & & 1.7 & 46 & 95 & \\
\hline 8 & Dimethylmaleate & & 5 & 50 & $>99$ & 98 \\
\hline 9 & Methylmethacrylate & & 5 & 568 & 86 & 98 \\
\hline 10 & Cinnamaldehyde & & 5 & 25 & 86 & 72 \\
\hline 11 & Crotonaldehyde & & 5 & 43 & 66 & 76 \\
\hline 12 & Benzylideneacetone & & 5 & 320 & 95 & 89 \\
\hline 13 & Cyclohexenone & & 3.8 & 269 & 96 & 82 \\
\hline
\end{tabular}

${ }^{a}$ Reaction conditions: $\mathrm{PHPh}_{2}$ and alkene $(0.48 \mathrm{mmol}), \mathbf{1}(0.024 \mathrm{mmol}, 5 \% \mathrm{~mol})$ in $0.7 \mathrm{~mL}$ of $\mathrm{C}_{6} \mathrm{D}_{6}$ at room temperature. For catalytic loadings of $1 \%$ or lower, the appropriate amount of catalyst was taken from a stock solution and the total volume was adjusted to $0.7 \mathrm{~mL}$. $[\mathrm{PHPh} 2]=[\mathrm{olefin}]=$ 2.71 (entry 2), 0.74 (entry 3), 1.23 (entry 5), 0.99 (entry 7), 0.99 (entry 13), M. ${ }^{b}$ Determined by ${ }^{1} \mathrm{H}$ NMR spectroscopy. ${ }^{c}$ The original position of the $\mathrm{C}=\mathrm{C}$ bond in the alkene is marked in red in the product. 
Nonetheless, $\mathrm{Ph}_{2} \mathrm{PhCH}_{2} \mathrm{CH}_{2} \mathrm{CO}_{2} \mathrm{Me}$ can be alternatively prepared in $1 \mathrm{~h}$ by the simple use of hydrated tetraethylammonium hydroxide. ${ }^{14}$

The related acrylonitrile (ACN), with a more electron withdrawing group (EWG) than methylacrylate (MeAC), ${ }^{15}$ was also hydrophosphanated with $\mathrm{PHPh}_{2}$. The catalysis was found to be slower than for MeAC, requiring $18 \mathrm{~min}$ at $\mathrm{rt}$; higher catalyst loadings ( $5 \% \mathrm{~mol}$ cat, entry 4 ) and around $2 \mathrm{~h}$ if more diluted catalytic solutions were used ( $1 \% \mathrm{~mol}$ cat, entry 5 ). These results were quite unexpected, since in a classic outer-sphere phospha-Michael addition, a more EWG at the $\alpha$ position of the olefin is expected to produce an increase in the reaction rate. Despite this, complex 1 operates more rapidly and with higher conversions in the hydrophosphanation of acrylonitrile with $\mathrm{PHPh}_{2}$ than other catalysts reported in the literature. As a matter of fact, a TOF of $30 \mathrm{~h}^{-1}$ has been reported by Morris ${ }^{16}$ with $\left[\mathrm{Ru}(\mathrm{Cp} *)\left(\mathrm{PPh}_{2}\right)\left(\mathrm{Ph}_{2} \mathrm{PCH}=\right.\right.$ $\left.\left.\mathrm{CHPPh}_{2}\right)\right]$ as catalyst $(1 \% \mathrm{~mol}, \mathrm{rt})$, whereas values of 10 and $2 \mathrm{~h}^{-1}$ were observed by Glueck ${ }^{6 \mathrm{~b}}$ with $\left[\mathrm{Pt}(\mathrm{dppe})\left(\mathrm{H}_{2} \mathrm{C}=\right.\right.$ $\mathrm{CHCN})]\left(10 \%\right.$ mol cat., $\left.50{ }^{\circ} \mathrm{C}\right)$ and Hey-Hawkins ${ }^{17}$ $\left(\left[\mathrm{Mo}(\mathrm{CO})_{5}\left(\mathrm{PH}_{2} \mathrm{Fc}\right)\right], 10 \% \mathrm{~mol}\right.$ cat., $\left.66{ }^{\circ} \mathrm{C}\right)$, respectively. Moreover, Waterman's zirconium catalyst, ${ }^{4 \mathrm{~g}}$ the ruthenium complex from Rosenberg, ${ }^{18}$ and the nickel complex from Webster ${ }^{19}$ required around $18-24 \mathrm{~h}$ with catalyst loadings of 5-10\%. Furthermore, no byproducts derived from the insertion of more than one molecule of alkene (telomerization) were observed in our case. ${ }^{8 \mathrm{~d}}$

Similar reaction times were observed if an EWG is incorporated at the $\beta$-position of the olefin, as observed for dimethyl fumarate as a substrate (fum, entries 6 and 7). A small influence of the cis/trans geometry on the reaction-rates was observed, since slightly longer reaction times were observed for dimethylmaleate (the cis-isomer of dimethyl fumarate, entry 8). Lower catalytic loadings (e.g., 1\% mol cat.) with these substrates were associated with lateral reactions that destroyed the catalyst. Nonetheless, complex 1 was robust enough to allow the reutilization of the catalytic solutions ( $5 \%$ mol cat.). Thus, after completion of the first catalytic run, dimethyl fumarate and $\mathrm{PHPh}_{2}$ were added again for five consecutive cycles without a significant decrease in the activity (see the Supporting Information).

Incorporation of a methyl group at the $\alpha$-position (entry 9) decreases the reaction rate considerably, which can be attributed to both the increase of the steric effects and the decrease of the positive charge on the $\alpha$-carbon.

The reaction is also tolerant to aldehydes, a poorly studied substrate in hydrophosphanation. ${ }^{20}$ The corresponding phosphanes were obtained in less than $1 \mathrm{~h}$ at rt. The catalysis with cinnamaldehyde (entry 10) with a more EWG than crotonaldehyde (entry 11) was found to be faster, suggesting that electronic effects are more important than steric ones. Small amounts (less than $1 \% \mathrm{~mol}$ ) of the corresponding 1hydroxy-1,3-diphosphanes derived from the hydrophosphanation of the $\mathrm{C}=\mathrm{O}$ group were observed. Moreover, the diphosphane from cinnamaldehyde was almost quantitatively formed (91.4\% yield) in 55 min if the catalysis was carried out with a $1: 10: 40$ ratio (1:aldehyde: $\mathrm{PHPh}_{2}$ ), while $73.6 \%$ of the diphosphane was formed when using crotonaldehyde under similar conditions even after $18 \mathrm{~h}$ of reaction.

Less-activated substrates with a ketone group such as benzylideneacetone (entry 12) and cyclohexenone (entry 13) required longer reaction times, whereas no reaction was observed with nonactivated substrates, such as styrene or 2,3- dimethyl-1-butene, even warming at $80{ }^{\circ} \mathrm{C}$. It is interesting to mention that enones as substrates have been typically hydrophosphanated by palladium complexes as catalyst, ${ }^{4 \mathrm{j}, 21}$ whereas a pincer-cobalt complex has been recently reported as suitable catalyst for the hydrophosphanation of the underexplored cyclohexenone. ${ }^{4 \mathrm{e}}$

From the catalytic solutions, the functionalized phosphanes were separated by chromatography and isolated in almost quantitative yields (see the Supporting Information).

DFT Studies. The extraordinary activity of complex $\mathbf{1}$ in the hydrophosphanation of methylacrylate (MeAC, entry 2) prompted us to analyze the first step of the catalytic cycle by DFT-methods, i.e., the reaction between $\mathbf{1}$ and MeAC, whose energy profile is shown in Figure 1.

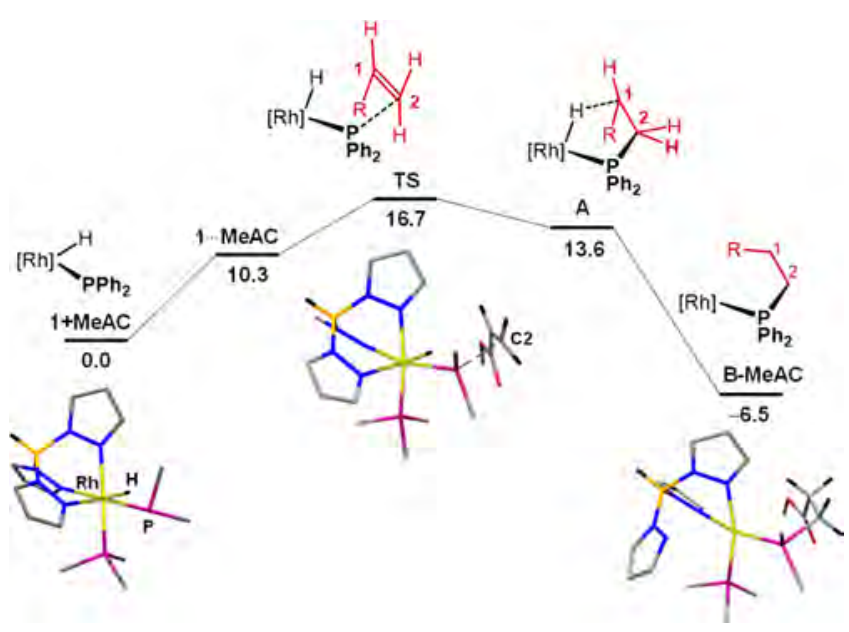

Figure 1. DFT computed (B3LYP-D3, 6-311G(d,p)/LanL2TZ(f)) Gibbs energy profile for the reaction of $\left[\mathrm{Rh}(\mathrm{Tp}) \mathrm{H}\left(\mathrm{PMe}_{3}\right)\left(\mathrm{PPh}_{2}\right)\right]$ (1) with methylacrylate. Relative $\Delta G_{298}$ values are given in $\mathrm{kcal} \mathrm{mol}^{-1}$. Only the $C^{\text {ipso }}$ of the diphenylphosphanido ligand is shown for clarity. Selected bond distances $(\AA)$ are the following: P-C2 $3.567(\mathbf{1} \cdots$

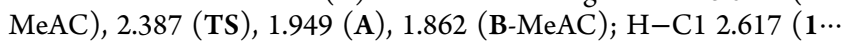
MeAC), 2.601 (TS), 2.283 (A). Color code is the following: $\mathrm{Rh}$ (yellow), O (red), N (blue), C (gray), B (orange), $\mathrm{H}$ (black). [Rh] = "Rh(Tp) $\left(\mathrm{PMe}_{3}\right)$ ", $\mathrm{R}=\mathrm{CO}_{2} \mathrm{Me}$.

After its formation, the initial adduct $1 \cdots \mathrm{MeAC}$ evolves to the intermediate $\mathbf{A}$ through a very accessible transition state TS (placed $16.7 \mathrm{kcal} \mathrm{mol}^{-1}$ above $1+\mathrm{MeAC}$ ) featuring an incipient $\mathrm{P}-\mathrm{C}$ bond. Intermediate $\mathbf{A}$ shows an almost strictly planar five-membered phosphametallacycle $\mathrm{Rh}-\mathrm{P}-\mathrm{C} 2-\mathrm{C} 1-$ $\mathrm{H}^{22}$ In addition, the sum of the three bond angles around $\mathrm{C} 1$ and $\mathrm{C} 2$ is $\sum^{\circ}=360.0^{\circ}$ and $333.0^{\circ}$, respectively. Therefore, C2 has an almost tetrahedral geometry (with the new $\mathrm{P}-\mathrm{C}$ bond), whereas $\mathrm{C} 1$ retains the $\mathrm{sp}^{2}$ hybridization. Moreover, the remaining $\mathrm{p}$ orbital of $\mathrm{C} 1$ directly points at the hydrido ligand, an indication of interaction between $\mathrm{C} 1$ and the hydride, clearly observed in the HOMO of the complex A (Figure 2). This additional $\mathrm{Rh}-\mathrm{H} \cdots \mathrm{C} 1$ interaction should stabilize intermediate $\mathbf{A}$, providing thus an easy path for the $\mathrm{P}-\mathrm{C}$ bond formation step. From A, the hydride transfer from rhodium to $\mathrm{C} 1$ takes place directly. This transfer gives the bis(phosphane)rhodium(I) intermediate, $\left[\mathrm{Rh}(\mathrm{Tp})\left(\mathrm{PMe}_{3}\right)\right.$ $\left.\left(\mathrm{PRPh}_{2}\right)\right]\left(\mathrm{R}=\mathrm{CH}_{2} \mathrm{CH}_{2} \mathrm{CO}_{2} \mathrm{Me}, \mathrm{B}-\mathrm{MeAC}\right)$, which was found to be $-6.5 \mathrm{kcal} \mathrm{mol}^{-1}$ more stable than $\mathbf{1}+\mathrm{MeAC}$.

The energy profile for this first step in the case of dimethyl fumarate (fum) was found to be quite similar, although in this 


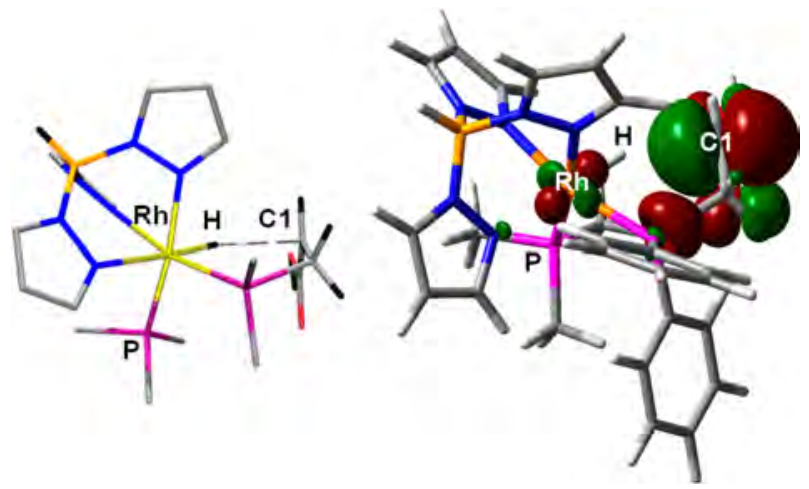

Figure 2. DFT computed geometry (B3LYP-D3, 6-311G $(\mathrm{d}, \mathrm{p}) /$ LanL2TZ(f)) for intermediate A (left) and HOMO of the complex (right).

case species $\mathbf{A}$ is not an intermediate but a transition state $\mathbf{T S}^{\prime}$ (Figure 3) placed $19.9 \mathrm{kcal} \mathrm{mol}^{-1}$ above $\mathbf{1}+$ fum.

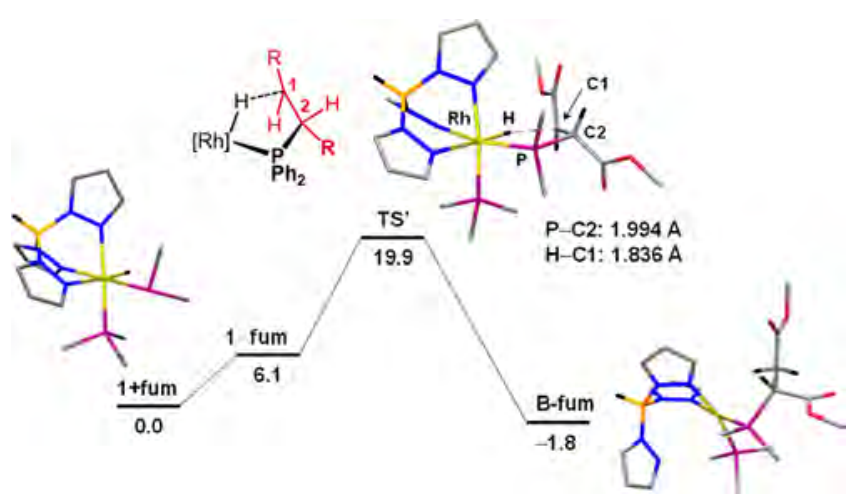

Figure 3. DFT computed (B3LYP-D3, 6-311G(d,p)/LanL2TZ(f)) Gibbs energy profile for the reaction of $\left[\mathrm{Rh}(\mathrm{Tp}) \mathrm{H}\left(\mathrm{PMe}_{3}\right)\left(\mathrm{PPh}_{2}\right)\right]$ (1) with dimethyl fumarate (fum). Relative $\Delta G_{298}$ values are given in $\mathrm{kcal} \mathrm{mol}^{-1}$. Only the $\mathrm{C}^{\mathrm{ipso}}$ of the diphenylphosphanido ligand is shown for clarity. Color code is the following: Rh (yellow), $\mathrm{O}$ (red), $\mathrm{N}$ (blue), C (gray), B (orange), H (black). [Rh] = "Rh(Tp)(PMe3)", $\mathrm{R}=\mathrm{CO}_{2} \mathrm{Me}$.

Noticeably, TS' results from a concerted approach of the two olefinic carbons of dimethyl fumarate to the hydride and the phosphanido groups to give a five-membered phosphametallacycle similar to that found in the intermediate A (Figure 1). Through $\mathbf{T S}$, the adduct $\mathbf{1} \cdots$ fum directly transforms into the rhodium(I) bis(phosphane) intermediate $[\mathrm{Rh}(\mathrm{Tp})$ $\left.\left(\mathrm{PMe}_{3}\right)\left(\mathrm{PRPh}_{2}\right)\right]\left(\mathrm{R}=\mathrm{CH}\left(\mathrm{CO}_{2} \mathrm{Me}\right) \mathrm{CH}_{2} \mathrm{CO}_{2} \mathrm{Me}\right.$, B-fum, Figure 3$)$ in a concerted outer-sphere single step.

The findings disclosed by DFT studies are remarkable. First and to the best of our knowledge, we are not aware of previous proposals of outer-sphere single-step mechanisms for the critical $\mathrm{P}-\mathrm{C}$ bond formation, and second, the relevant role of the hydride ligand is unprecedented in olefin hydrophosphanation. Moreover, the beneficial $\mathrm{Rh}-\mathrm{H} \cdots \mathrm{C} 1$ interaction observed in intermediate A (Figure 2) and $\mathbf{T S}^{\prime}$ (Figure 3) requires an electrophilic hydride because of the negative charge accumulated on $\mathrm{C} 1$. In this scenario it is expected that acrylonitrile (with a more EWG at the $\alpha$-position than methylacrylate $)^{15}$ is hydrophosphanated more slowly than MeAC (as experimentally observed), as a result of the partial reduction of the negative charge at the $\alpha$-carbon that weakens the positive $\mathrm{Rh}-\mathrm{H} \cdots \mathrm{C} 1$ interaction. On the whole, the $\mathrm{P}-\mathrm{Rh}-$
$\mathrm{H}$ moiety seems to act as a 1,3-dipole in these reactions, which could be considered as 1,3-dipolar cycloadditions. Furthermore, addition of ${ }^{t} \mathrm{BuOH}(5 \mathrm{mmol})$ to the catalytic solutions in the acrylonitrile and dimethyl fumarate cases did not produce appreciable changes in the reaction rate, supporting again the "click" scenario (1,3-cycloaddition) for the key $\mathrm{P}-\mathrm{C}$ and $\mathrm{C}-\mathrm{H}$ bond formation steps. Notice that if a free carbanion were present, the catalysis should be accelerated by ${ }^{t} \mathrm{BuOH} .{ }^{8 \mathrm{~d}}$

Stoichiometric Studies. Further information about the reliability of the DFT profiles in Figures 1 and 3 as well as the fundamental role of the hydride ligand was gathered through several additional selected experiments at stoichiometric level.

In the case of dimethyl fumarate, for which the equilibrium

$$
\text { B-fum }+ \text { fum } \leftrightarrows\left[\mathrm{Rh}(\mathrm{Tp})(\text { fum })\left(\mathrm{PMe}_{3}\right)\right](\mathbf{2})+\mathrm{Ph}_{2} \mathrm{P}-\mathrm{R}
$$

is fully shifted to the right $\left(\Delta G^{0}=-3.1 \mathrm{kcal} \mathrm{mol}^{-1}\right.$ from DFT), the reaction of $\left[\mathrm{Rh}(\mathrm{Tp}) \mathrm{H}\left(\mathrm{PMe}_{3}\right)\left(\mathrm{PPh}_{2}\right)\right]$ (1) with dimethyl fumarate was analyzed by NMR spectroscopy (Scheme 2). It

Scheme 2. Reaction of $\left[\mathrm{Rh}(\mathrm{Tp}) \mathrm{H}\left(\mathrm{PMe}_{3}\right)\left(\mathrm{PPh}_{2}\right)\right]$ (1) with Dimethyl Fumarate, $\mathrm{R}=\mathrm{CO}_{2} \mathrm{Me}, \mathrm{Tp}^{\prime}=\kappa^{2}-\mathrm{Tp}$

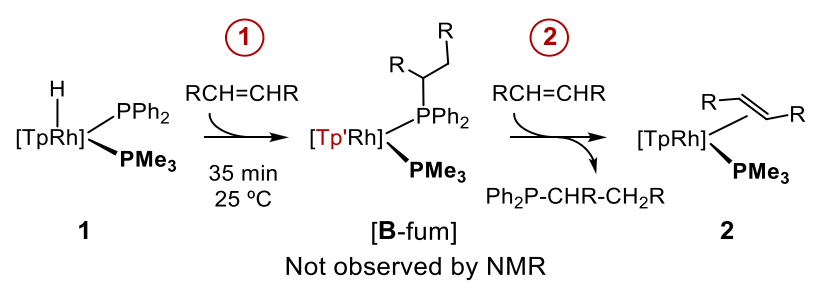

required 2 molequiv of the olefin to reach completion, and the products were found to be $\left[\mathrm{Rh}(\mathrm{Tp})(\right.$ fum $\left.)\left(\mathrm{PMe}_{3}\right)\right](2)^{23}$ and the functionalized phosphane, $\mathrm{Ph}_{2} \mathrm{P}-\mathrm{R}\left(\mathrm{R}=\mathrm{CH}\left(\mathrm{CO}_{2} \mathrm{Me}\right)\right.$ $\mathrm{CH}_{2} \mathrm{CO}_{2} \mathrm{Me}$ ).

Interestingly, if the reaction is carried out in a 1:1 molar ratio, complex 2 and the free phosphane were again obtained, but in this case $50 \%$ of complex 1 remains unreacted. This observation provides a clear indication that step 1 is the ratedetermining step. Then, the reaction rate can be expressed as ${ }^{24}$

$$
\text { rate }=-\frac{[\mathbf{1}]}{\mathrm{d} t}=k_{1}[\mathbf{1}][\text { fum }]=2 k_{1}[\mathbf{1}]^{2}
$$

A plot of $1 /[1]$ vs time proved to be linear with a slope $=2 k_{1}$ (see the Supporting Information). The value of $k_{1}=4.65 \times$ $10^{-2} \mathrm{M}^{-1} \mathrm{~s}^{-1}$ translates to a free energy barrier of ca. $19.3 \mathrm{kcal}$ $\mathrm{mol}^{-1}(298 \mathrm{~K})$ using the Eyring-Polanyi equation. ${ }^{25}$

Goodness of this single-point calculation for $\Delta G^{\ddagger}$ was experimentally confirmed by carrying out a full study of the reaction in the temperature range $213-307 \mathrm{~K}$ (Eyring plot). The activation parameters $\Delta H^{\ddagger}=6.3 \pm 0.2 \mathrm{kcal} \mathrm{mol}^{-1}$ and $\Delta S^{\ddagger}=-44.3 \pm 0.6 \mathrm{cal} \mathrm{mol}^{-1} \mathrm{~K}^{-1}$ (extracted from the straight line obtained) gave a value for $\Delta G_{298}^{\ddagger}=19.5 \mathrm{kcal} \mathrm{mol}^{-1}$, which is similar to that estimated from the single-point approximation. Both values for $\Delta G^{\ddagger}$ are in excellent agreement with that obtained from DFT calculations $\left(19.9 \mathrm{kcal} \mathrm{mol}^{-1}\right)$. Moreover, the large and negative activation entropy can be seen as diagnostic of a highly ordered transition state as that shown in Figure 3. Furthermore, a parallel experiment with $\left[\mathrm{Rh}(\mathrm{Tp}) \mathrm{D}\left(\mathrm{PMe}_{3}\right)\left(\mathrm{PPh}_{2}\right)\right]\left(\mathbf{1}^{\mathrm{D}}\right)$ and dimethyl fumarate (in 1:2 molar ratio) under identical conditions gave a ratio $k_{\mathrm{H}} / k_{\mathrm{D}}=$ 1.31. This small kinetic isotope effect (KIE) agrees with the simple elongation of the $\mathrm{Rh}-\mathrm{H}$ bond in the transition state 
TS' (Figure 3). Accordingly, a value of 1.3 was estimated from DFT-studies.

For methyl acrylate (MeAC), the corresponding equilibrium B-MeAC $+\mathrm{MeAC} \leftrightarrows\left[\mathrm{Rh}(\mathrm{Tp})(\mathrm{MeAC})\left(\mathrm{PMe}_{3}\right)\right](3)+\mathrm{Ph}_{2} \mathrm{P}-$ $\mathrm{R}^{\prime}\left(\mathrm{R}^{\prime}=\mathrm{CH}_{2} \mathrm{CH}_{2} \mathrm{CO}_{2} \mathrm{Me}\right)$ is fully shifted to the left $\left(\Delta G^{0}=\right.$ $+2.7 \mathrm{kcal} \mathrm{mol}^{-1}$ from DFT) so that attention was paid on the reaction of $\left[\mathrm{Rh}(\mathrm{Tp})(\mathrm{MeAC})\left(\mathrm{PMe}_{3}\right)\right]$ (3) with diphenylphosphane. This reaction also requires 2 molequiv of $\mathrm{PHPh}_{2}$ to reach completion, and the products were found to be $\left[\mathrm{Rh}(\mathrm{Tp}) \mathrm{H}\left(\mathrm{PMe}_{3}\right)\left(\mathrm{PPh}_{2}\right)\right]$ (1) and $\mathrm{Ph}_{2} \mathrm{P}-\mathrm{R}^{\prime}$ (Scheme 3). In

Scheme 3. Reaction of $\left[\mathrm{Rh}(\mathrm{Tp})(\mathrm{MeAC})\left(\mathrm{PMe}_{3}\right)\right]$ (3) with $\mathrm{PHPh}_{2}, \mathrm{R}=\mathrm{CO}_{2} \mathrm{Me}, \mathrm{Tp}^{\prime}=\kappa^{2}-\mathrm{Tp}$

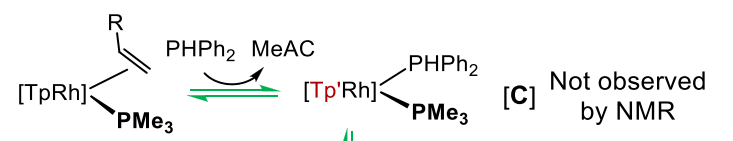

3

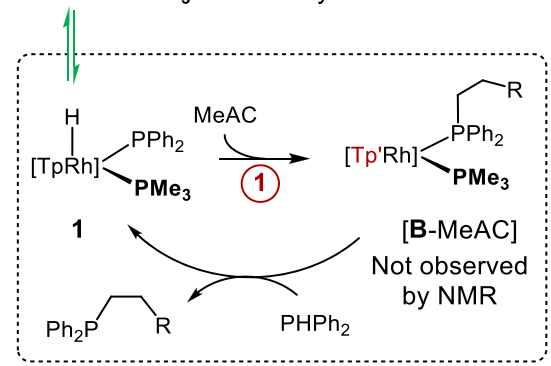

this case, replacement of MeAC by $\mathrm{PHPh}_{2}$ to render intermediate $\left[\mathrm{Rh}(\mathrm{Tp})\left(\mathrm{PHPh}_{2}\right)\left(\mathrm{PMe}_{3}\right)\right](\mathrm{C})$ and then $[\mathrm{Rh}$ (Tp) $\left.\mathrm{H}\left(\mathrm{PMe}_{3}\right)\left(\mathrm{PPh}_{2}\right)\right]$ (1) was so fast that complex 3 was not present anymore in the first ${ }^{1} \mathrm{H}$ NMR spectra (recorded after $3.5 \mathrm{~min}$ of reaction). Moreover, in this spectrum complex 1 and the phosphane $\mathrm{Ph}_{2} \mathrm{P}-\mathrm{R}^{\prime}$, along with small amounts of free methyl acrylate and $\mathrm{PHPh}_{2}$ in a stoichiometric ratio, were present (Scheme 3).

Because the reaction reached completion after ca. $15 \mathrm{~min}$, four ${ }^{1} \mathrm{H}$ NMR spectra were recorded; evolution of the concentration of free methyl acrylate vs time was found to be exponential, whereas the concentration of $\mathbf{1}$ remained almost constant (see the Supporting Information).

Consequently, what we were indeed observing in the monitored $15 \mathrm{~min}$ corresponds to the catalytic formation of $\mathrm{Ph}_{2} \mathrm{P}-\mathrm{R}^{\prime}$ by complex 1 in a scenario where $[1] \approx[3]^{0}$ (Scheme 3). Therefore,

$$
\text { rate }=k_{1}[\mathbf{1}][\mathrm{MeAC}]=k_{1}[3]^{0}[\mathrm{MeAC}]=k_{\text {obs }}[\mathrm{MeAC}]
$$

The value of $k_{\text {obs }}=6.71 \times 10^{-3}$ corresponds to $k_{1}=1.18 \mathrm{M}^{-1}$ $\mathrm{s}^{-1}$, which translates to a free energy barrier of ca. $17.3 \mathrm{kcal}$ $\mathrm{mol}^{-1}(298 \mathrm{~K})$ for step 1 in Scheme 3 by using the EyringPolanyi equation. This value fits considerably well with that obtained from DFT studies $\left(16.7 \mathrm{kcal} \mathrm{mol}^{-1}\right.$ (298 K), Figure $1)$. Moreover, since the full transformation of $[\mathrm{Rh}(\mathrm{Tp})$ $\left.(\mathrm{MeAC})\left(\mathrm{PMe}_{3}\right)\right]$ (3) into $\left[\mathrm{Rh}(\mathrm{Tp}) \mathrm{H}\left(\mathrm{PMe}_{3}\right)\left(\mathrm{PPh}_{2}\right)\right]$ (1) was found to be faster than the $\mathrm{P}-\mathrm{C}$ bond formation reaction (Scheme 3), it can be concluded that the activation energy for the $\mathrm{P}-\mathrm{H}$ bond cleavage is lower than $17.3 \mathrm{kcal} \mathrm{mol}^{-1}$, and consequently, the previously reported value of ca. $20 \mathrm{kcal}$ $\mathrm{mol}^{-1}$ (from DFT) was most probably overestimated. ${ }^{13}$

Additionally, the first part of the reaction (from 3 to 1 ) was analyzed by DFT calculations. The first step (eq a, Scheme 4) requires dissociation of a pyrazolate arm in 3 to allow the coordination of diphenylphosphane, which renders accessible
Scheme 4. Elemental Steps for the Transformation of 3 into 1 and Plausible Intermediates for Alternative Inner-Sphere Mechanisms, $T \mathbf{p}^{\prime}=\kappa^{2}-\mathrm{Tp}^{a}$

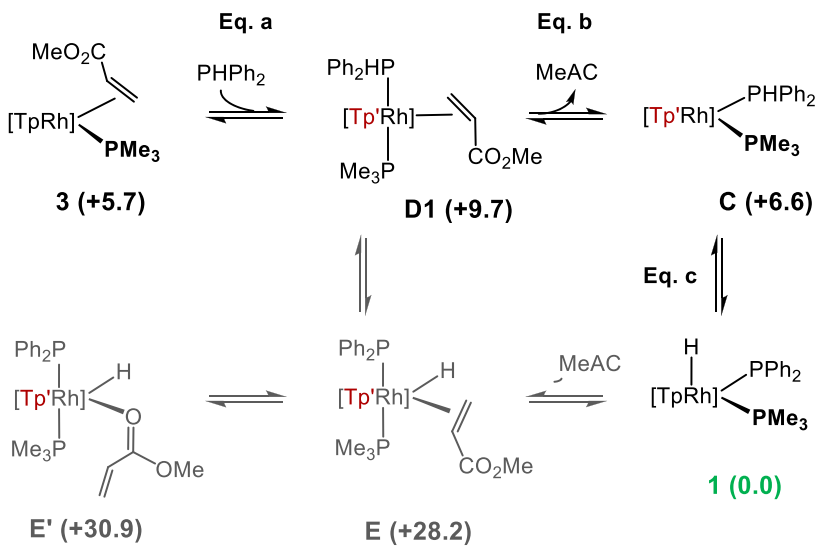

${ }^{a}$ Thermodynamic Gibbs energy values (DFT computed, B3LYP-D3, 6-311G(d,p)/LanL2TZ(f)) relative to $\mathbf{1}+\mathrm{MeAC}$ (in green) are shown in parentheses, in $\mathrm{kcal} \mathrm{mol}^{-1}$.

intermediates of the type $\left[\mathrm{Rh}\left(\mathrm{Tp}^{\prime}\right)\left(\mathrm{PMe}_{3}\right)\left(\mathrm{PHPh}_{2}\right)(\mathrm{MeAC})\right]$ (D, $\left.\mathrm{Tp}^{\prime}=\kappa^{2}-\mathrm{Tp}\right)$; the trans isomer (D1, Scheme 4) was found to be slightly more stable than the cis counterpart in $0.9 \mathrm{kcal}$ $\mathrm{mol}^{-1}$. From $\mathrm{D}$, extrusion of the olefin gives the square-planar intermediate $\left[\mathrm{Rh}\left(\mathrm{Tp}^{\prime}\right)\left(\mathrm{PMe}_{3}\right)\left(\mathrm{PHPh}_{2}\right)\right](\mathrm{C})$, in which an easy $\mathrm{P}-\mathrm{H}$ bond activation reaction produces complex 1 . This step (eq c) is the driving force for the full transformation of 3 into 1.

At this point, the alternative inner-sphere mechanism was tested by modeling the "hypothetical" intermediate $\left[\mathrm{Rh}\left(\mathrm{Tp}^{\prime}\right)\right.$ $\mathrm{H}\left(\mathrm{PMe}_{3}\right)\left(\mathrm{PPh}_{2}\right)$ (olefin)] (E), which would be the key species for further hydride insertion and $\mathrm{P}-\mathrm{C}$ bond formation reactions (Scheme 1). Complex $\mathbf{E}$ could be the result of the $\mathrm{P}-\mathrm{H}$ bond cleavage in $\mathrm{D}$, or alternatively, it can arise from the dissociation of a pyrazolate arm in $\mathbf{1}$ to allow olefin coordination. In any case, complex $\mathbf{E}$ was found to be 28.2 $\mathrm{kcal} \mathrm{mol}^{-1}$ above $\mathbf{1}+\mathrm{MeAC}$, and consequently, this alternative was discarded. Moreover, the "hypothetical" isomer with methyl acrylate $\mathrm{O}$-coordinated $\left(\mathbf{E}^{\prime}\right)$ was also modeled since this complex would be the first step for a further intramolecular nucleophilic attack of the phosphanido to the olefin, as proposed by Leung in palladium chemistry. ${ }^{21 a, 26}$ However, complex $\mathbf{E}^{\prime}$ was found to be even higher in energy than $\mathbf{E}$ (Scheme 4). Moreover, both complexes (E and $\mathbf{E}^{\prime}$ ) lie above the transition state TS $\left(16.7 \mathrm{kcal} \mathrm{mol}^{-1}\right)$ shown in Figure 1 for the novel "click step" reported here, which is the lowest energy pathway we have found by DFT calculations.

The last point analyzed at stoichiometric level concerns the prominent role of the hydride ligand commented above. To this end, attention was focused on the related complex $\left[\mathrm{Rh}(\mathrm{Tp}) \mathrm{Cl}\left(\mathrm{PMe}_{3}\right)\left(\mathrm{PPh}_{2}\right)\right](4)$, in which the hydride ligand in 1 has been formally replaced by a chloride one.

Complex 4 was prepared from the reaction of $[\mathrm{Rh}(\mathrm{Tp}) \mathrm{H}$ $\left.\left(\mathrm{PMe}_{3}\right)\left(\mathrm{PPh}_{2}\right)\right]$ (1) with $\mathrm{ClCH}_{2} \mathrm{CO}_{2} \mathrm{Me}$ (see the Supporting Information) and further characterized by analytical and spectroscopic data, including an X-ray diffraction analysis (Figure 4). In the complex, the rhodium atom shows a distorted octahedral environment bound to a fac-Tp ligand and to trimethylphosphane, the terminal phosphanido, and chlorido ligands. The geometry around the phosphanido 


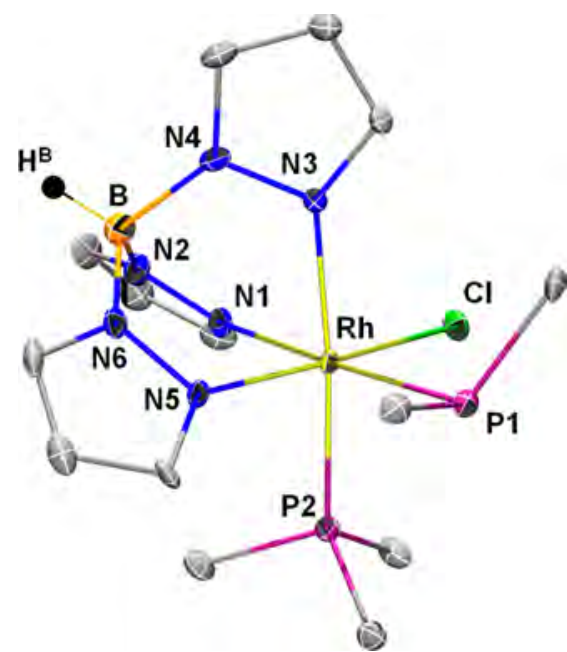

Figure 4. Molecular structure (ORTEP, ellipsoids set at 50\% probability) of complex $\left[\mathrm{Rh}(\mathrm{Tp}) \mathrm{Cl}\left(\mathrm{PMe}_{3}\right)\left(\mathrm{PPh}_{2}\right)\right](4)$. One of the two similar independent molecules is showed. Selected bond distances $[\AA]$ and angles [deg] are the following: Rh-P1 2.404(2)/2.399(2), $\mathrm{Rh}-\mathrm{P} 2$ 2.283(2)/2.288(2), $\mathrm{Rh}-\mathrm{Cl} 2.356(2) / 2.357(2), \mathrm{Rh}-\mathrm{N} 1$ $2.180(6) / 2.191(7), \mathrm{Rh}-\mathrm{N} 3$ 2.131(6)/2.131(7), Rh-N5 2.075(7)/ 2.073(8), P1-Rh-N1 176.7(2)/175.0(2), P2-Rh-N3 174.2(2)/

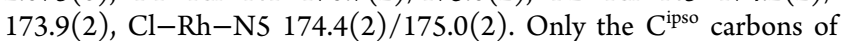
the phenyl groups are shown for clarity.

phosphorus atom (P1) reveals that the lone pair does not interact with $\mathrm{Rh}$ resulting in a $\mathrm{Rh}-\mathrm{P} 1$ single bond. Thus, the environment of P1 is pyramidal with the sum of the three bond angles amounting to $\sum^{\circ}=314.6(3) / 316.2(3)^{\circ}$.

According to its formulation, complex 4 shows two signals corresponding to the $\mathrm{PPh}_{2}$ and $\mathrm{PMe}_{3}$ groups as doublets of doublets in the ${ }^{31} \mathrm{P}\left\{{ }^{1} \mathrm{H}\right\}$ NMR spectrum at $\delta=56.3(J(\mathrm{P}, \mathrm{Rh})=$ $61 \mathrm{~Hz})$ and $0.2(J(\mathrm{P}, \mathrm{Rh})=119 \mathrm{~Hz}) \mathrm{ppm}$, respectively. The value of $J(\mathrm{P}, \mathrm{Rh})$ for the terminal phosphanido ligand was found to be smaller than those corresponding to the phosphane. This difference can be attributed to a substantial reduction in the $\sigma$-orbital character of the $\mathrm{Rh}-\mathrm{PR}_{2}$ bond as compared to the $\mathrm{Rh}$-phosphane, ${ }^{12}$ providing thus a useful tool for the identification of the terminal phosphanido ligand.

The reaction of $\left[\mathrm{Rh}(\mathrm{Tp}) \mathrm{Cl}\left(\mathrm{PMe}_{3}\right)\left(\mathrm{PPh}_{2}\right)\right]$ (4) with dimethyl fumarate was carried out in the presence of $1 \mathrm{~mol}$ of $\mathrm{PHPh}_{2}$ to attain protonolysis of the expected carbanion that regenerates complex 4 (Scheme 5).

Scheme 5. Reaction of $\left[\mathrm{Rh}(\mathrm{Tp}) \mathrm{Cl}\left(\mathrm{PMe}_{3}\right)\left(\mathrm{PPh}_{2}\right)\right]$ (4) with Dimethyl Fumarate and Diphenylphosphane, $\mathrm{R}=\mathrm{CO}_{2} \mathrm{Me}$

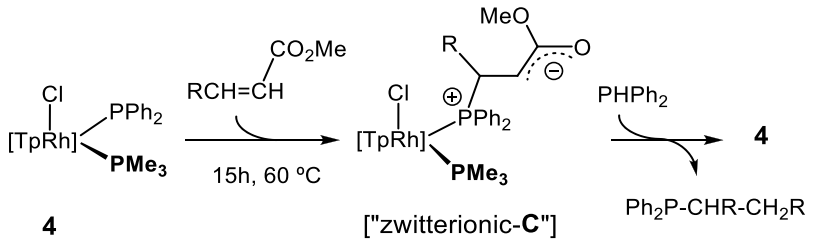

The reaction succeeded, but it required around $15 \mathrm{~h}$ at 60 ${ }^{\circ} \mathrm{C}$ to reach completion. ${ }^{27}$ This experiment definitively confirms the beneficial role of the hydrido ligand in the facile hydrophosphanation of dimethyl fumarate with the hydrido complex $\mathbf{1}$.

Kinetic Studies and Proposed Mechanism. On the basis of these experimental and theoretical results, we propose the catalytic cycle shown in Scheme 6. The first step corresponds to the interaction of catalyst $\mathbf{1}$ with the olefin to

Scheme 6. Proposed Catalytic Cycle for Olefin Hydrophosphanation with $\mathrm{PHPh}_{2}$ Catalyzed by Complex 1, $\mathbf{T} \mathbf{p}^{\prime}=\kappa^{2}-\mathbf{T p}$

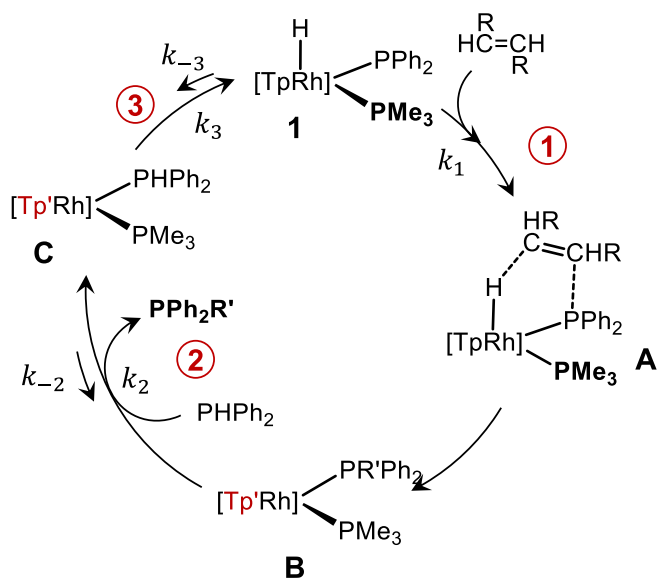

yield intermediate A (TS' for dimethyl fumarate), which directly evolves to the bis(phosphane)rhodium(I) complex B. Next, a ligand exchange reaction of the functionalized phosphane by $\mathrm{PHPh}_{2}$ gives intermediate $\mathrm{C}$, for which an easy $\mathrm{P}-\mathrm{H}$ bond activation reaction (almost immediate at $\mathrm{rt}^{12}$ ) regenerates the catalyst, closing thus the catalytic cycle.

Further support for the proposed catalytic cycle was gathered from kinetic studies. A first analysis of the catalysis under standard conditions [cat.]:[olefin]:[ $\left.\mathrm{PHPh}_{2}\right] \quad 1: 20: 20$ (1:5000:5000 for MeAC) revealed mainly two different behaviors. For substrates whose entry is marked in red (Table 1), plots of [olefin] vs time gave very good exponential fittings, whereas for those marked in green, an excellent fit to straight lines were obtained when plotting $[\mathrm{PH}]^{0} \mathrm{Ln}[\mathrm{PH}]-$ $[\mathrm{PH}]\left([\mathrm{PH}]=\left[\mathrm{PHPh}_{2}\right]\right)$ vs time. Figure 5 shows a couple of representative examples, while all of them can be found in the Supporting Information.

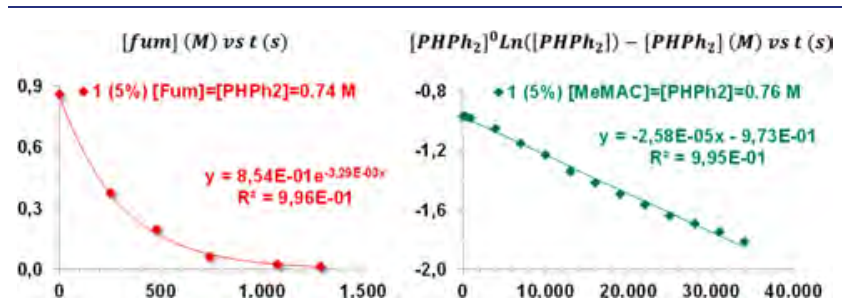

Figure 5. Plots of [fum] (fum = dimethyl fumarate, left) vs time (s) and $[\mathrm{PH}]^{0} \mathrm{Ln}[\mathrm{PH}]-[\mathrm{PH}]\left([\mathrm{PH}]=\left[\mathrm{PHPh}_{2}\right]\right.$, right $)$ vs time $(\mathrm{s})$ for the catalytic hydrophosphanation of dimethyl fumarate (in red) and methyl methacrylate (in green) using complex $\mathbf{1}$ as catalyst.

Moreover, a more detailed study on the hydrophosphanation of dimethyl fumarate and acrylonitrile (both marked in red in Table 1) revealed some interesting differences. Thus, for dimethyl fumarate, a zeroth-order dependence of the reaction rate on $\left[\mathrm{Ph}_{2} \mathrm{PH}\right]$ and first-order dependence on [fum] and on [1] were obtained, whereas in the acrylonitrile case, a firstorder dependence was observed for the three components $\left[\mathrm{PHPh}_{2}\right],[\mathrm{ACN}]$, and $[\mathbf{1}]$ (see the Supporting Information). 
Accordingly, plots of $\operatorname{Ln}\left(V^{0} /[1]^{0}\right)$ versus $\operatorname{Ln}\left(\left[\mathrm{PHPh}_{2}\right]^{0}\right)$, $\operatorname{Ln}\left(V^{0} /[\mathbf{1}]^{0}\right)$ versus $\operatorname{Ln}\left([\text { fum }]^{0}\right)$, and $\operatorname{Ln}\left(k_{\text {obs }}\right)$ versus $\operatorname{Ln}\left([\mathbf{1}]^{0}\right)$ were linear with slopes of $0.083,0.92$, and 0.99 , respectively, for the hydrophosphanation of dimethyl fumarate, while these values transform into $1.15,1.16$ and 1.17 , respectively, for acrylonitrile hydrophosphanation.

This apparent contradiction of different rate-laws for the same catalytic cycle can be rationalized according to the rate law corresponding to the catalytic cycle shown in Scheme 6:

$$
\text { rate }=-\frac{\mathrm{d}[\text { ole }]}{\mathrm{d} t}=\frac{k_{1} k_{2}[\mathbf{1}]^{0}[\mathrm{PH}][\text { ole }]}{k_{1}[\mathrm{ole}]+k_{2}[\mathrm{PH}]+\frac{k_{-2} k_{1}}{k_{3}}[\text { ole }][\mathrm{PR}]}
$$

where ole $=$ olefin, $\mathrm{PH}=\mathrm{PHPh}_{2}, \mathrm{PR}=$ functionalized phosphane, from which three main scenarios have been observed.

(i) The first possibility involves the term $k_{2}[\mathrm{PH}]$ in the denominator being larger than the other two in such a way that the rate law simplifies to rate $=k_{1}[\mathbf{1}]^{0}[\mathrm{ole}]$, and it can be expected for substrates that benefit from a rapid phosphane exchange reaction (step 2) and relatively slow step 1 . Since this exchange should be easier with less electron-rich functionalized phosphanes, it is not strange that dimethyl fumarate and dimethyl maleate, both leading to $\mathrm{Ph}_{2} \mathrm{P}-\mathrm{CH}\left(\mathrm{CO}_{2} \mathrm{Me}\right)$ $\mathrm{CH}_{2} \mathrm{CO}_{2} \mathrm{Me}$ (the most electron-poor phosphane of those considered), follow this rate law. Accordingly, a zeroth-order dependence of the reaction rate on $\left[\mathrm{Ph}_{2} \mathrm{PH}\right]$ and first-order dependence on [olefin] and on [1] are expected, as experimentally observed in the case of dimethyl fumarate. For these substrates, step 1 is thought to be the ratedetermining step in full agreement with the high value of the experimentally measured entropy (see above).

(ii) In the case of substrates for which

$$
k_{2}[\mathrm{PH}]+k_{1}[\mathrm{ole}] \gg \frac{k_{-2} k_{1}}{k_{3}}[\mathrm{ole}][\mathrm{PR}] \quad\left(k_{1} \approx k_{2}\right)
$$

the rate law simplifies under catalytic conditions $\left([\mathrm{PH}]^{0}=\right.$ $[\text { ole }]^{0}=[\mathrm{S}]^{0}$ ) to

$$
\text { rate }=\frac{k_{1} k_{2}[\mathbf{1}]^{0}[\mathrm{PH}][\text { ole }]}{k_{1}[\text { ole }]+k_{2}[\mathrm{PH}]}=\frac{k_{1} k_{2}}{k_{1}+k_{2}}[\mathbf{1}]^{0}[\mathrm{~S}]=k_{\text {cat }}[\mathbf{1}]^{0}[\mathrm{~S}]
$$

Consequently, plots of [olefin] vs time are expected to give exponential fittings under catalytic conditions. Moreover, in the presence of an excess of olefin,

$$
k_{1}[\mathrm{ole}]^{0}>k_{2}[\mathrm{PH}] \Rightarrow \text { rate }=k_{2}[\mathbf{1}]^{0}[\mathrm{PH}]
$$

whereas in the presence of an excess of $\mathrm{PHPh}_{2}$,

$$
k_{2}[\mathrm{PH}]^{0}>k_{1}[\mathrm{ole}] \Rightarrow \text { rate }=k_{1}[\mathbf{1}]^{0}[\mathrm{ole}]
$$

so that a first order dependence on both olefin and $\mathrm{PHPh}_{2}$ is expected under pseudo-first-order conditions. This scenario corresponds to that experimentally found for acrylonitrile (and most probably for methyl acrylate). As a matter of fact, Figure 6 shows a couple of catalysis under identical pseudo-first-order conditions for $\mathrm{PHPh}_{2}$ (in black) and acrylonitrile (in red).

A nice exponential fitting was obtained for both experiments, with almost identical values of $k_{\mathrm{obs}}=k_{1}[\mathbf{1}]^{0}$ and $k_{2}[\mathbf{1}]^{0}$, which clearly support the initial premise of $k_{1} \approx k_{2}$.

(iii) For substrates that show the reverse situation with equilibrium 2 shifted to species $\mathbf{B}$, for which

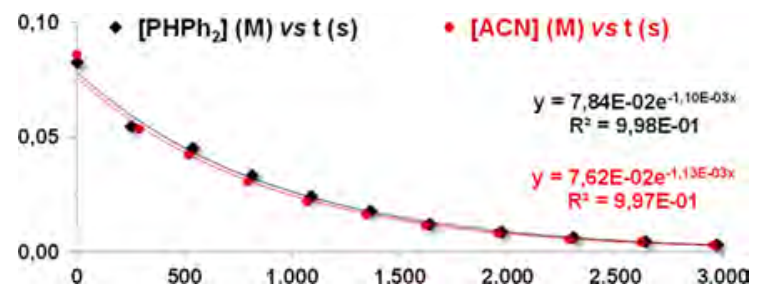

Figure 6. Plots of $\left[\mathrm{PHPh}_{2}\right](\mathrm{M})$ (in black) and $[\mathrm{ACN}] \mathrm{M}$ (in red) vs time (s) under pseudo-first-order conditions: $[1]^{0}:[\mathrm{ACN}]^{0}:\left[\mathrm{PHPh}_{2}\right]^{0}$ $=1: 50: 10$ in black and $1: 10: 50$ in red. $[1]^{0}=0.0083 \mathrm{M}$ in both cases, taken from a stock solution.

$$
\frac{k_{-2} k_{1}}{k_{3}}[\mathrm{ole}][\mathrm{PR}] \gg k_{2}[\mathrm{PH}]+k_{1}[\text { ole }]
$$

the rate law becomes

$$
\text { rate }=k_{3} K_{\text {eq2 } 2}[\mathbf{1}]^{0} \frac{[\mathrm{PH}]}{[\mathrm{PH}]^{0}-[\mathrm{PH}]}
$$

and it is followed by substrates marked in green in Table 1 $\left(k_{\mathrm{obs}}=k_{3} K_{\mathrm{eq} 2}[\mathbf{1}]^{0}\right)$, which hydrophosphanated more slowly by catalyst 1 than the red ones due to the poisoning of the catalyst by the product to some extent. Indeed, the resulting phosphanes in these cases are electronically richer than those arising from methyl acrylate, acrylonitrile, and dimethyl fumarate/maleate.

Additionally, the progress of the selected catalysis in the presence of an excess of equimolar amounts of $\mathrm{PHPh}_{2}$ and $\mathrm{PDPh}_{2}$ (ratio cat.:fum: $\mathrm{PHPh}_{2}: \mathrm{PDPh}_{2}=1: 20: 100: 100$, intermolecular competition ${ }^{28}$ ) was monitored to determine the isotope effect. This method was chosen mainly because olefin functionalization by $\mathrm{PHPh}_{2}$ and $\mathrm{PDPh}_{2}$ occurs under exactly the same conditions, avoiding experimental errors, and because the ratio of the functionalized phosphanes $\left(\mathrm{PR}_{\mathrm{H}} / \mathrm{PR}_{\mathrm{D}}\right)$ can be measured by NMR spectroscopy with very good precision. Values of $\mathrm{PR}_{\mathrm{H}} / \mathrm{PR}_{\mathrm{D}}=1.28,1.22$, and 1.27 were respectively observed for methyl acrylate, acrylonitrile, and dimethyl fumarate (three substrates marked in red in Table 1, scenarios i and ii), which agree with that obtained for step 1 (dimethyl fumarate) at stoichiometric level. On the contrary, a larger value of 2.33 was measured for cyclohexanone (marked in green, scenario iii), which could be related to the cleavage of the $\mathrm{P}-\mathrm{H}$ bond (or alternatively, previous $\mathrm{PHPh}_{2}$ coordination to intermediate $\mathbf{B}),{ }^{28}$ in the rate-determining step.

Interestingly, in the particular case of dimethyl fumarate and cyclohexanone, where two chiral carbons are formed in the hydrophosphanation process, one enantiomeric pair was formed in our case, as evidenced by ${ }^{1} \mathrm{H}$ and ${ }^{2} \mathrm{H}$ NMR spectroscopy (see the Supporting Information). Most probably, the observed enantiomeric pair corresponds to that arising from the syn-addition of the hydrido and phosphanido ligands to the olefin, as expected from the click-step shown in Figures 1 and 3. Note that in a stepwise scenario, through a zwitterionic intermediate with a carbanion as proposed by Glueck, ${ }^{\text {3a }}$ free rotation around the $\mathrm{C} 1-\mathrm{C} 2$ bond would allow the entry of the hydrido ligand on the other side so that the second enantiomeric pair (corresponding to the anti-addition) can be expected, at least in some extension. In other words, the observation of a single enantiomeric pair corroborates the outer-sphere single-step mechanism for the critical $\mathrm{P}-\mathrm{C}$ bond formation reported here. 
Finally, the plausible inhibition of the catalyst by the olefin, suitable to sequester part of the catalyst as the rhodium(I) complexes $\left[\mathrm{Rh}(\mathrm{Tp})(\right.$ olefin $\left.)\left(\mathrm{PMe}_{3}\right)\right]$, was tested estimating (by DFT studies) the thermodynamic free energies for the equilibria: $\left[\mathrm{Rh}(\mathrm{Tp})(\right.$ olefin $\left.)\left(\mathrm{PMe}_{3}\right)\right]+\mathrm{PHPh}_{2} \leftrightarrows \mathbf{1}+$ olefin.

Values of $\Delta G^{0}=-1.2,-5.7$, and -4.8 were obtained for dimethyl fumarate, methyl acrylate, and acrylonitrile, respectively. Consequently, the equilibria are shifted to right and the main catalytic cycle that operates is that shown in Scheme 6.

\section{CONCLUSIONS}

The hydrido-phosphanido rhodium complex $[\mathrm{Rh}(\mathrm{Tp}) \mathrm{H}$ $\left.\left(\mathrm{PMe}_{3}\right)\left(\mathrm{PPh}_{2}\right)\right](\mathbf{1})$, containing a tripodal ligand $(\mathrm{Tp})$ and an additional phosphane ligand, readily catalyzes the addition of diphenylphosphane to a wide range of olefins. Its good activity likely arises from a catalytic cycle including three wellseparated steps: (i) an outer-sphere $\mathrm{P}-\mathrm{C}$ and $\mathrm{H}-\mathrm{C}$ bond formation likely through a 1,3-dipolar cycloaddition, (ii) a replacement reaction of the functionalized phosphane by $\mathrm{PHPh}_{2}$, and (iii) an easy $\mathrm{P}-\mathrm{H}$ bond activation reaction that regenerates the catalyst. Stoichiometric, kinetic, and DFT studies provided further support for this picture, in which the critical $\mathrm{P}-\mathrm{C}$ bond formation step takes place through intermediates (or TS) in which both the phosphanido and the hydrido ligands interact with the $\alpha$ - and $\beta$-carbons of the alkene, respectively, in a cooperative way. The beneficial role of the $\mathrm{Rh}-\mathrm{H} \cdots \mathrm{C} 1$ interaction, which avoids side-reactions (as telomerization) and facilitates the hydrogen transfer from rhodium to $\mathrm{C} 1$, is remarkable. In full agreement, the related complex $\left[\mathrm{Rh}(\mathrm{Tp}) \mathrm{Cl}\left(\mathrm{PMe}_{3}\right)\left(\mathrm{PPh}_{2}\right)\right]$ (4), which lacks the electrophilic arm (the hydride present in 1), was found to be a poor catalyst. We believe that the findings reported here have important implications for hydrophosphanation reactions, especially in scenarios associated with $\mathrm{P}-\mathrm{H}$ bond cleavage steps, and represent substantial progress from a mechanistic point of view. Knowing that both the nucleophilicity of the phosphanido ligand and the electrophilicity ${ }^{29}$ of the hydrido ligand play key roles may help develop new catalysts for the "green syntheses" of phosphanes and related reactions. Further studies on this topic are currently in progress.

\section{ASSOCIATED CONTENT}

\section{SI Supporting Information}

The Supporting Information is available free of charge at https://pubs.acs.org/doi/10.1021/jacs.0c11010.

Experimental details, catalytic and kinetic studies, and selected NMR spectra of complexes and phosphanes (PDF)

Cartesian coordinates for optimized (DFT) structures of complexes, intermediates, and transition states (XYZ)

Crystallographic data for complex 4 (CIF)

Crystallographic data for complex $\left[\mathrm{Rh}(\mathrm{Tp}) \mathrm{Cl}_{2}\left(\mathrm{PMe}_{3}\right)\right]$ (CIF)

\section{AUTHOR INFORMATION}

\section{Corresponding Author}

Cristina Tejel - Departamento de Química Inorgánica, Instituto de Síntesis Química y Catálisis Homogénea (ISQCH), CSIC-Universidad de Zaragoza, 50009 Zaragoza, Spain; ㅈorcid.org/0000-0003-3306-0635; Email: ctejel@ unizar.es
Authors

Víctor Varela-Izquierdo - Departamento de Química Inorgánica, Instituto de Síntesis Química y Catálisis Homogénea (ISQCH), CSIC-Universidad de Zaragoza, 50009 Zaragoza, Spain; 이이.org/0000-0002-78068959

Ana M. Geer - Departamento de Química Inorgánica, Instituto de Síntesis Química y Catálisis Homogénea (ISQCH), CSIC-Universidad de Zaragoza, 50009 Zaragoza, Spain; (1) orcid.org/0000-0003-1115-6759

Janeth Navarro - Departamento de Química Inorgánica, Instituto de Síntesis Química y Catálisis Homogénea (ISQCH), CSIC-Universidad de Zaragoza, 50009 Zaragoza, Spain; orcid.org/0000-0002-2549-4487

José A. López - Departamento de Química Inorgánica, Instituto de Síntesis Química y Catálisis Homogénea (ISQCH), CSIC-Universidad de Zaragoza, 50009 Zaragoza, Spain; 이이.org/0000-0003-4500-1974

Miguel A. Ciriano - Departamento de Química Inorgánica, Instituto de Síntesis Química y Catálisis Homogénea (ISQCH), CSIC-Universidad de Zaragoza, 50009 Zaragoza, Spain; ○ orcid.org/0000-0002-7188-8014

Complete contact information is available at: https://pubs.acs.org/10.1021/jacs.0c11010

\section{Author Contributions}

${ }^{\dagger}$ V.V.-I., A.M.G., and J.N. contributed equally.

\section{Notes}

The authors declare no competing financial interest.

The crystallographic data have been deposited with the Cambridge Crystallographic Data Centre (1965870 and 1965871).

\section{ACKNOWLEDGMENTS}

The generous financial support from AEI/FEDER, UE (CTQ2017-83421-P), Gobierno de Aragón/FEDER, UE (GA/FEDER, Inorganic Molecular Architecture Group E08_17R) is gratefully acknowledged. A.M.G. and V.V.-I. thank MINECO/FEDER for a JdC contract and a FPI fellowship, respectively. The Centro de Supercomputación de Galicia (CESGA) is also gratefully acknowledged for generous allocation of time.

\section{REFERENCES}

(1) (a) Allen, D. W. Phosphines and related C-P bonded compounds. Organophosphorus Chem. 2016, 45, 1-50. (b) Beletskaya, I. P.; Ananikov, V. P.; Khemchyan, L. L. Synthesis of Phosphorous Compounds via Metal-Catalyzed Addition of $\mathrm{P}-\mathrm{H}$ Bond to Unsaturated Organic Molecules. In Phosphorus Compounds: Advanced Tools in Catalysis and Material Sciences; Peruzzini, M., Gonsalvi, L., Eds.; Springer: Dordrecht, The Netherlands, 2011; pp 213-264. (c) Chen, L.; Zou, Y.-X. Recent progress in the synthesis of phosphorus containing indole derivatives. Org. Biomol. Chem. 2018, 16, 7544-7556. (d) Montchamp, J.-L. Phosphinate Chemistry in the 21st Century: A Viable Alternative to the Use of Phosphorus Trichloride in Organophosphorus Synthesis. Acc. Chem. Res. 2014, 47, 77-87.

(2) (a) Montchamp, J.-L. Challenges and solutions in phosphinate Chemistry. Pure Appl. Chem. 2019, 91, 113-120. (b) Wauters, I.; Debrouwer, W.; Stevens, C. V. Preparation of phosphines through CP bond formation. Beilstein J. Org. Chem. 2014, 10, 1064-1096. (c) Arbuzova, S. N.; Gusarova, N. K.; Trofimov, B. A. Nucleophilic and free-radical additions of phosphines and phosphine chalcogenides to alkenes and alkynes. ARKIVOC 2006, 2006, 12-16. 
(3) (a) Glueck, D. S. Metal-Catalyzed P-C Bond Formation via P$\mathrm{H}$ Oxidative Addition: Fundamentals and Recent Advances. J. Org. Chem. 2020, 85, 14276-14285. (b) Waterman, R. TriamidoamineSupported Zirconium Compounds in Main Group Bond-Formation Catalysis. Acc. Chem. Res. 2019, 52, 2361-2369. (c) Greenberg, S.; Stephan, D. W. Stoichiometric and catalytic activation of $\mathrm{P}-\mathrm{H}$ and P-P bonds. Chem. Soc. Rev. 2008, 37, 1482-1489. (d) Wicht, D. K.; Glueck, D. S. Hydrophosphination and Related Reactions. In Catalytic Heterofunctionalization. From Hydroamination to Hydrozirconation; Togni, A., Grutzmacher, H., Eds.; Wiley-VCH: Weinheim, Germany, 2001; pp 143-170.

(4) (a) Li, Y.-B.; Tian, H.; Yin, L. Copper(I)-Catalyzed Asymmetric 1,4-Conjugate Hydrophosphination of $\alpha, \beta$-Unsaturated Amides. J. Am. Chem. Soc. 2020, 142, 20098-20106. (b) Barrett, A. N.; Sanderson, H. J.; Mahon, M. F.; Webster, R. L. Hydrophosphination using $\left[\mathrm{GeCl}\left\{\mathrm{N}\left(\mathrm{SiMe}_{3}\right)_{2}\right\}_{3}\right]$ as a pre-catalyst. Chem. Commun. 2020, 56, 13623-13626. (c) Lapshin, I. V.; Cherkasov, A. V.; Asachenko, A. F.; Trifonov, A. A. $\operatorname{Ln}(\mathrm{II})$ amido complexes coordinated by ringexpanded N-heterocyclic carbenes - promising catalysts for olefin hydrophosphination. Chem. Commun. 2020, 56, 12913-12916. (d) Dannenberg, S. G.; Waterman, R. A bench-stable copper photocatalyst for the rapid hydrophosphination of activated and unactivated alkenes. Chem. Commun. 2020, 56, 14219-14222. (e) Nolla-Saltiel, R.; Geer, A. M.; Taylor, L. J.; Churchill, O.; Davies, E. S.; Lewis, W.; Blake, A. J.; Kays, D. L. Hydrophosphination of Activated Alkenes by a Cobalt(I) Pincer Complex. Adv. Synth. Catal. 2020, 362, 3148-3157. (f) Selikhov, A. N.; Plankin, G. S.; Cherkasov, A. V.; Shavyrin, A. S.; Louyriac, E.; Maron, L.; Trifonov, A. A. Thermally Stable $\mathrm{Ln}$ (II) and $\mathrm{Ca}(\mathrm{II})$ Bis(benzhydryl) Complexes: Excellent Precatalysts for Intermolecular Hydrophosphination of C-C Multiple Bonds. Inorg. Chem. 2019, 58, 5325-5334. (g) Novas, B. T.; Bange, C. A.; Waterman, R. Photocatalytic Hydrophosphination of Alkenes and Alkynes Using Diphenylphosphine and Triamidoamine-Supported Zirconium. Eur. J. Inorg. Chem. 2019, 2019, 1640-1643. (h) Basiouny, M. M. I.; Dollard, D. A.; Schmidt, J. A. R. Regioselective Single and Double Hydrophosphination and Hydrophosphinylation of Unactivated Alkynes. ACS Catal. 2019, 9, 7143-7153. (i) Pollard, V. A.; Young, A.; McLellan, R.; Kennedy, A. R.; Tuttle, T.; Mulvey, R. E. Lithium-AluminateCatalyzed Hydrophosphination Applications. Angew. Chem., Int. Ed. 2019, 58, 12291-12296. (j) Tay, W. S.; Yang, X.-Y.; Li, Y.; Pullarkat, S. A.; Leung, P.-H. Investigating palladium pincer complexes in catalytic asymmetric hydrophosphination and hydroarsination. Dalton Trans. 2019, 48, 4602-4610. (k) Zhang, Y.; Qu, Li; Wang, Y.; Yuan, D.; Yao, Y.; Shen, Q. Neutral and Cationic Zirconium Complexes Bearing Multidentate Aminophenolato Ligands for Hydrophosphination Reactions of Alkenes and Heterocumulenes. Inorg. Chem. 2018, 57, 139-149. (1) Bange, C. A.; Conger, M. A.; Novas, B. T.; Young, E. R.; Liptak, M. D.; Waterman, R. Light-Driven, Zirconium-Catalyzed Hydrophosphination with Primary Phosphines. ACS Catal. 2018, 8, 6230-6238. (m) Ackley, B. J.; Pagano, J. K.; Waterman, R. Visiblelight and thermal driven double hydrophosphination of terminal alkynes using a commercially available iron compound. Chem. Commun. 2018, 54, 2774-2776. (n) Bezzenine-Lafollée, S.; Gil, R.; Prim, D.; Hannedouche, J. First-Row Late Transition Metals for Catalytic Alkene Hydrofunctionalisation: Recent Advances in $\mathrm{C}-\mathrm{N}$, $\mathrm{C}-\mathrm{O}$ and $\mathrm{C}-\mathrm{P}$ Bond Formation. Molecules 2017, 22, 1901. (o) Hirano, K.; Miura, M. Recent advances in diphosphination of alkynes and alkenes. Tetrahedron Lett. 2017, 58, 4317-4322. (p) Bange, C. A.; Waterman, R. Challenges in Catalytic Hydrophosphination. Chem. - Eur. J. 2016, 22, 12598-12605. (q) Trifonov, A. A.; Basalov, I. V.; Kissel, A. A. Use of organolanthanides in the catalytic intermolecular hydrophosphination and hydroamination of multiple C-C bonds. Dalton Trans. 2016, 45, 19172-19193. (r) Okugawa, Y.; Hirano, K.; Miura, M. Copper-Catalyzed Vicinal Diphosphination of Styrenes: Access to 1,2-Bis(diphenylphosphino)ethane-Type Bidentate Ligands from Olefins. Angew. Chem., Int. Ed. 2016, 55, 13558-13561. (s) Bange, C. A.; Waterman, R. ZirconiumCatalyzed Intermolecular Double Hydrophosphination of Alkynes with a Primary Phosphine. ACS Catal. 2016, 6, 6413-6416. (t) Pullarkat, S. A. Recent Progress in Palladium-Catalyzed Asymmetric Hydrophosphination. Synthesis 2016, 48, 493-503. (u) Koshti, V.; Gaikwad, S.; Chikkali, S. H. Contemporary avenues in catalytic $\mathrm{P}-\mathrm{H}$ bond addition reaction: A case study of hydrophosphination. Coord. Chem. Rev. 2014, 265, 52-73. (v) Ghebreab, M. B.; Bange, C. A.; Waterman, R. Intermolecular ZirconiumCatalyzed Hydrophosphination of Alkenes and Dienes with Primary Phosphines. J. Am. Chem. Soc. 2014, 136, 9240-9243. (w) Pullarkat, S. A.; Leung, P.-H. Chiral Metal Complex-Promoted Asymmetric Hydrophosphinations. Top. Organomet. Chem. 2011, 43, 145-166. (x) Delacroix, O.; Gaumont, A. C. Hydrophosphination of Unactivated Alkenes, Dienes and Alkynes: A Versatile and Valuable Approach for the Synthesis of Phosphines. Curr. Org. Chem. 2005, 9, 1851-1882. (y) Baillie, C.; Xiao, J. Catalytic Synthesis of Phosphines and Related Compounds. Curr. Org. Chem. 2003, 7, 477-514.

(5) (a) Rosenberg, L. Mechanisms of Metal-Catalyzed Hydrophosphination of Alkenes and Alkynes. ACS Catal. 2013, 3, 28452855. (b) Glueck, D. S. Recent Advances in Metal-Catalyzed C-P Bond Formation. Top. Organomet. Chem. 2010, 31, 65-100. (c) Waterman, R. Metal-phosphido and -phosphinidene complexes in $\mathrm{P}-\mathrm{E}$ bond-forming reactions. Dalton Trans. 2009, 18-26. (d) Glueck, D. S. Metal-catalyzed nucleophilic carbon-heteroatom (C-X) bond formation: the role of $\mathrm{M}-\mathrm{X}$ intermediates. Dalton Trans. 2008, 5276-5286.

(6) (a) Kovacik, I.; Wicht, D. K.; Grewal, N. S.; Glueck, D. S.; Incarvito, C. D.; Guzei, I. A.; Rheingold, A. L. Pt(Me-Duphos)Catalyzed Asymmetric Hydrophosphination of Activated Olefins: Enantioselective Synthesis of Chiral Phosphines. Organometallics 2000, 19, 950-953. (b) Wicht, D. K.; Kourkine, I. V.; Kovacik, I.; Glueck, D. S.; Concolino, T. E.; Yap, G. P. A.; Incarvito, C. D.; Rheingold, A. L. Platinum-Catalyzed Acrylonitrile Hydrophosphination. $\mathrm{P}-\mathrm{C}$ Bond Formation via Olefin Insertion into a $\mathrm{Pt}-\mathrm{P}$ Bond. Organometallics 1999, 18, 5381-5394. (c) Wicht, D. K.; Kourkine, I. V.; Lew, B. M.; Nthenge, J. M.; Glueck, D. S. Platinum-Catalyzed Acrylonitrile Hydrophosphination via Olefin Insertion into a $\mathrm{Pt}-\mathrm{P}$ Bond. J. Am. Chem. Soc. 1997, 119, 5039-5040.

(7) (a) Rajpurohit, J.; Kumar, P.; Shukla, P.; Shanmugam, M.; Shanmugam, M. Mechanistic Investigation of Well-Defined Cobalt Catalyzed Formal E-Selective Hydrophosphination of Alkynes. Organometallics 2018, 37, 2297-2304. (b) Shulyupin, M. O.; Kazankova, M. A.; Beletskaya, I. P. Catalytic Hydrophosphination of Styrenes. Org. Lett. 2002, 4, 761-763. (c) Costa, E.; Pringle, P. G.; Worboys, K. Chemoselective platinum $(0)$-catalysed hydrophosphination of ethyl acrylate. Chem. Commun. 1998, 49-50. (d) Costa, E.; Pringle, P. G.; Smith, M. B.; Worboys, K. Self-replication of tris(cyanoethyl)phosphine catalysed by platinum group metal complexes. J. Chem. Soc., Dalton Trans. 1997, 4277-4282. (e) Pringle, P. G.; Smith, M. B. Platinum(0)-catalysed Hydrophosphination of Acrylonitrile. J. Chem. Soc., Chem. Commun. 1990, 1701-1702.

(8) (a) Chadwick, A. C.; Heckenast, M. A.; Race, J. J.; Pringle, P. G.; Sparkes, H. A. Self-Replication of Chelating Diphosphines via $\mathrm{Pt}(0)$ Catalyzed Hydrophosphination. Organometallics 2019, 38, 38713879. (b) Scriban, C.; Glueck, D. S.; Zakharov, L. N.; Kassel, W. S.; DiPasquale, A. G.; Golen, J. A.; Rheingold, A. L. P-C and C-C Bond Formation by Michael Addition in Platinum-Catalyzed Hydrophosphination and in the Stoichiometric Reactions of Platinum Phosphido Complexes with Activated Alkenes. Organometallics 2006, 25, 5757-5767. (c) Kovacik, I.; Scriban, C.; Glueck, D. S. Regiochemistry of Platinum-Catalyzed Hydrophosphination of a Diene. Formation of the Chiral Diphosphine $\mathrm{Et}_{2} \mathrm{PCH}(\mathrm{CN}) \mathrm{CH}$ $\left(\mathrm{CH}_{2} \mathrm{CH}_{2} \mathrm{CN}\right) \mathrm{PEt}_{2}$ via Monophosphine Intermediates. Organometallics 2006, 25, 536-539. (d) Scriban, C.; Kovacik, I.; Glueck, D. S. A Protic Additive Suppresses Formation of Byproducts in PlatinumCatalyzed Hydrophosphination of Activated Olefins. Evidence for P$\mathrm{C}$ and $\mathrm{C}-\mathrm{C}$ Bond Formation by Michael Addition. Organometallics 2005, 24, 4871-4874. 
(9) Han, L.-B.; Tilley, T. D. Selective Homo- and Heterodehydrocouplings of Phosphines Catalyzed by Rhodium Phosphido Complexes. J. Am. Chem. Soc. 2006, 128, 13698-13699.

(10) Böhm, V. P. W.; Brookhart, M. Dehydrocoupling of Phosphanes Catalyzed by a Rhodium(I) Complex. Angew. Chem., Int. Ed. 2001, 40, 4694-4696.

(11) Di Giuseppe, A.; De Luca, R.; Castarlenas, R.; Pérez-Torrente, J. J.; Crucianelli, M.; Oro, L. A. Double hydrophosphination of alkynes promoted by rhodium: the key role of an N-heterocyclic carbene ligand. Chem. Commun. 2016, 52, 5554-5557.

(12) Varela-Izquierdo, V.; Geer, A. M.; de Bruin, B.; López, J. A.; Ciriano, M. A.; Tejel, C. Rhodium Complexes in $\mathrm{P}-\mathrm{H}$ Bond Activation Reactions. Chem.-Eur. J. 2019, 25, 15915-15928.

(13) Geer, A. M.; Serrano, A. L.; de Bruin, B.; Ciriano, M. A.; Tejel, C. Terminal Phosphanido Rhodium Complexes Mediating Catalytic $\mathrm{P}-\mathrm{P}$ and $\mathrm{P}-\mathrm{C}$ Bond Formation. Angew. Chem., Int. Ed. 2015, 54, $472-475$.

(14) Blinn, D. A.; Button, R. S.; Farazi, V.; Neeb, M. K.; Tapley, C. L.; Trehearne, T. E.; West, S. D.; Kruger, T. L.; Storhoff, B. N. Addition of diphenylphosphine to Michael-type olefins: the preparation of phosphine-nitrile and phosphine-ester ligands. J. Organomet. Chem. 1990, 393, 143-152.

(15) Remya, G. S.; Suresh, C. H. Quantification and classification of substituent effects in organic chemistry: a theoretical molecular electrostatic potential study. Phys. Chem. Chem. Phys. 2016, 18, 20615-20626.

(16) Sues, P. E.; Lough, A. J.; Morris, R. H. Reactivity of Ruthenium Phosphido Species Generated through the Deprotonation of a Tripodal Phosphine Ligand and Implications for Hydrophosphination. J. Am. Chem. Soc. 2014, 136, 4746-4760.

(17) Pritzwald-Stegmann, J. R. F.; Lönnecke, P.; Hey-Hawkins, E. Hydrophosphination reactions with transition metal ferrocenylphosphine complexes. Dalton Trans. 2016, 45, 2208-2217.

(18) Belli, R. G.; Burton, K. M. E.; Rufh, S. A.; McDonald, R.; Rosenberg, L. Inner- and Outer-Sphere Roles of Ruthenium Phosphido Complexes in the Hydrophosphination of Alkenes. Organometallics 2015, 34, 5637-5646.

(19) Webster, R. L. Room Temperature Ni(II) Catalyzed Hydrophosphination and Cyclotrimerization of Alkynes. Inorganics 2018, 6, 120.

(20) See for example the following: (a) Chen, Y.-R.; Duan, W.-L. Palladium-Catalyzed 1,4-Addition of Diarylphosphines to $\alpha, \beta$ Unsaturated Aldehydes. Org. Lett. 2011, 13, 5824-5826. (b) Carlone, A.; Bartoli, G.; Bosco, M.; Sambri, L.; Melchiorre, P. Organocatalytic Asymmetric Hydrophosphination of $\alpha, \beta$-Unsaturated Aldehydes. Angew. Chem., Int. Ed. 2007, 46, 4504-4506. (c) Ibrahem, I.; Rios, R.; Vesely, J.; Hammar, P.; Eriksson, L.; Himo, F.; Córdova, A. Angew. Chem., Int. Ed. 2007, 46, 4507-4510. (d) Hoye, P. A. T.; Pringle, P. G.; Smith, M. B.; Worboys, K. Hydrophosphination of formaldehyde catalysed by tris-(hydroxymethyl)phosphine complexes of platinum, palladium or nickel. J. Chem. Soc., Dalton Trans. 1993, 269-274.

(21) See for example the following: (a) Yang, X.-Y.; Jia, Y.-X.; Tay, W. S.; Li, Y.; Pullarkat, S. A.; Leung, P.-H. Mechanistic insights into the role of PC- and PCP-type palladium catalysts in asymmetric hydrophosphination of activated alkenes incorporating potential coordinating heteroatoms. Dalton Trans. 2016, 45, 13449-13455. (b) Song, Y.-C.; Dai, G. F.; Xiao, F.; Duan, W.-L. Palladium-catalyzed enantioselective hydrophosphination of enones for the synthesis of chiral P,N-compounds. Tetrahedron Lett. 2016, 57, 2990-2993. (c) Hao, X.-Q.; Huang, J.-J.; Wang, T.; Lv, J.; Gong, J.-F.; Song, M.-P. PCN Pincer Palladium(II) Complex Catalyzed Enantioselective Hydrophosphination of Enones: Synthesis of Pyridine Functionalized Chiral Phosphine Oxides as $\mathrm{NC}_{\mathrm{sp}}{ }^{3} \mathrm{O}$ Pincer Preligands. J. Org. Chem. 2014, 79, 9512-9530. (d) Hao, X.-Q.; Zhao, Y.-W.; Yang, J.-J.; Niu, J.-L.; Gong, J.-F.; Song, M.-P. Enantioselective Hydrophosphination of Enones with Diphenylphosphine Catalyzed by Bis(imidazoline) NCN Pincer Palladium(II) Complexes. Organometallics 2014, 33, 1801-1811. (e) Huang, Y.; Pullarkat, S. A.; Li, Y.; Leung, P.-H. Palladacycle-Catalyzed Asymmetric Hydrophosphination of Enones for Synthesis of $\mathrm{C}^{*}$ - and $\mathrm{P}^{*}$-Chiral Tertiary Phosphines. Inorg. Chem. 2012, 51, 2533-2540. (f) Huang, Y.; Chew, R. J.; Li, Y.; Pullarkat, S. A.; Leung, P.-H. Direct Synthesis of Chiral Tertiary Diphosphines via $\mathrm{Pd}(\mathrm{II})$-Catalyzed Asymmetric Hydrophosphination of Dienones. Org. Lett. 2011, 13, 5862-5865. (g) Huang, Y.; Pullarkat, S. A.; Li, Y.; Leung, P.-H. Palladium(II)-catalyzed asymmetric hydrophosphination of enones: efficient access to chiral tertiary phosphines. Chem. Commun. 2010, 46, 6950-6952. (h) Feng, J.-J.; Chen, X.-F.; Shi, M.; Duan, W.-L. Palladium-Catalyzed Asymmetric Addition of Diarylphosphines to Enones toward the Synthesis of Chiral Phosphines. J. Am. Chem. Soc. 2010, 132, 5562-5563.

(22) The max dev of the best plane was found to be $0.041 \AA$.

(23) Complexes 2 and 3 were easily prepared from the reaction of $\left[\mathrm{RhTp}\left(\mathrm{PMe}_{3}\right)\left(\mathrm{C}_{2} \mathrm{H}_{4}\right)\right]$ with dimethyl fumarate and methylacrylate, respectively (see the Supporting Information).

(24) Because complex B-fum was not observed, it can be assumed that $[\mathbf{1}]^{0} \approx[\mathbf{1}]+[\mathbf{2}]$ and $[\text { fum }]^{0}=[$ fum $]+[\mathbf{2}]+[\mathrm{PR}](\mathrm{PR}=$ functionalized phosphane), and since PR is formed simultaneously with complex 2 (through step 2) $\Rightarrow[2]=[\mathrm{PR}]$ at any time. Taking into account the experimental conditions $[\text { fum }]^{0}=2[\mathbf{1}]^{0}$, a simple calculation leads to $[$ fum $]=2[1]$ at any time. Consequently, the rate law becomes rate $=2 k_{1}[\mathbf{1}]^{2}$.

(25) $k=\frac{k_{\mathrm{B}} T}{h} \mathrm{e}^{\Delta G^{\ddagger} /(R T)}, k_{\mathrm{B}}=$ Boltzmann constant, $R=$ gas constant, $h$ = Planck constant, and assuming a transmission coefficient of 1 .

(26) See for example the following: (a) Chew, R. J.; Li, X.-R.; Li, Y.; Pullarkat, S. A.; Leung, P.-H. Pd-Catalyzed Enantiodivergent and Regiospecific phospha-Michael Addition of Diphenylphosphine to 4oxo-Enamides: Efficient Access to Chiral Phosphinocarboxamides and Their Analogues. Chem. - Eur. J. 2015, 21, 4800-4804. (b) Chew, R. J.; Teo, K. Y.; Huang, Y.; Li, B.-B.; Li, Y.; Pullarkat, S. A.; Leung, P.-H. Enantioselective phospha-Michael addition of diarylphosphines to $\beta, \gamma$-unsaturated $\alpha$-ketoesters and amides. Chem. Commun. 2014, 50, $8768-8770$.

(27) Under similar experimental conditions a $5 \%$ of conversion in the phosphane $\mathrm{Ph}_{2} \mathrm{P}-\mathrm{CH}\left(\mathrm{CO}_{2} \mathrm{Me}\right) \mathrm{CH}_{2} \mathrm{CO}_{2} \mathrm{Me}$ was observed in the absence of complex 4.

(28) Simmons, E. M.; Hartwig, J. F. On the Interpretation of Deuterium Kinetic Isotope Effects in $\mathrm{C}-\mathrm{H}$ Bond Functionalizations by Transition-Metal Complexes. Angew. Chem., Int. Ed. 2012, 51, 3066-3072.

(29) Waldie, K. M.; Ostericher, A. L.; Reineke, M. H.; Sasayama, A. F.; Kubiak, C. P. Hydricity of Transition-Metal Hydrides: Thermodynamic Considerations for $\mathrm{CO}_{2}$ Reduction. ACS Catal. 2018, 8, 1313-1324. 